\title{
SUBGLOTTIC AND CLOSED ENDOTRACHEAL SUCTIONING VERSUS OPEN ENDOTRACHEAL SUCTIONING- EFFECT ON VENTILATOR-ASSOCIATED PNEUMONIA RATES AND LENGTH OF INTENSIVE CARE UNIT STAY
}

\author{
Gulshan Dhawan ${ }^{1}$
}

${ }^{1}$ Classified Specialist, Department of Anaesthesia, Military Hospital, Panagarh, West Bengal, India.

ABSTRACT
BACKGROUND
Ventilator Associated Pneumonia (VAP) is a complication of invasive mechanical ventilatory support. One of the methods of
preventing VAP is adequate suctioning.
This study compared the incidence of VAP and length of Intensive Care Unit (ICU) stay among patients managed by two
different suctioning techniques, grouped as Group OES and Group SS + CES. Group OES patients were managed by Open
Endotracheal Suctioning. Group SS + CES patients were managed by subglottic suctioning and closed endotracheal suctioning.

\section{MATERIALS AND METHODS}

Patients in Group OES ( $n=20)$ were intubated with conventional ETT and those in Group SS + CES (n= 20) with ETT having subglottic suction port above the cuff. VAP was defined as a Clinical Pulmonary Infection Score of $>6$ with a positive quantitative endotracheal culture in patients on ventilator for $>48 \mathrm{~h}$. Chi-square test and Mann-Whitney U-test were performed for statistical analysis.

\section{RESULTS}

Nine patients in Group OES and three patients in Group SS + CES developed VAP. VAP rate was significantly lesser in patients intubated with ETT having subglottic suction port above the cuff and managed by subglottic and closed endotracheal suctioning. ICU stay was significantly lesser in Group SS + CES (median, 6 days; interquartile range: 5 - 7) compared to patients in Group OES (median, 7; interquartile range: 6 - 9).

\section{CONCLUSION}

The VAP rate and length of ICU stay were significantly lesser among patients intubated with the ETTs having subglottic suction port above the cuff and managed by subglottic suctioning and closed endotracheal suctioning.

\section{KEY WORDS}

Endotracheal Tube, Ventilator-Associated Pneumonia, Open Endotracheal Suctioning, Subglottic Suctioning, Closed Endotracheal Suctioning.

HOW TO CITE THIS ARTICLE: Dhawan G. Subglottic and closed endotracheal suctioning versus open endotracheal suctioningeffect on ventilator-associated pneumonia rates and length of intensive care unit stay. J. Evolution Med. Dent. Sci. 2018;7(34): 3730-3733, DOI: $10.14260 /$ jemds/2018/838

\section{BACKGROUND}

The normal human respiratory tract possesses a variety of defense mechanisms that protect the lung from infection. For Example: Anatomic barriers such as glottis and larynx; cough reflexes; tracheobronchial secretions; mucociliary lining; cell mediated and humoral immunity; dual phagocytic system that involves both macrophages and neutrophils. In mechanically ventilated patients, majority of these defenses are bypassed, hence the increased incidence of lower respiratory infections. As suggested by infrequent association of Ventilator Associated Pneumonia (VAP) with bacteraemia, the majority of these infections appear to result from aspiration of potential pathogens that have colonised the mucosal surfaces of oropharyngeal airways. ${ }^{1}$

Intubation of the patient not only compromises the natural barrier between the oropharynx and trachea, but may

'Financial or Other Competing Interest': None.

Submission 11-07-2018, Peer Review 04-08-2018,

Acceptance 10-08-2018, Published 16-08-2018.

Corresponding Author:

Dr. Gulshan Dhawan,

House No. 767, Sector 40-A,

Chandigarh, Punjab, India.

E-mail: gulshan.dhawan@gmail.com

DOI: $10.14260 /$ jemds $/ 2018 / 838$

\section{(c) $(7)$}

also facilitate the entry of bacteria into the lung by pooling and leakage of contaminated secretions (Microaspirations) around the endotracheal tube cuff. These microaspirations of contaminated oropharyngeal and gastric secretions could be one of the causes of developing VAP. ${ }^{1}$ Microcuff tubes made of polyurethane cuffs having lesser chances of folds and channel formation contributes to reduction in incidence of VAP. ${ }^{2}$

Ventilator Associated Pneumonia (VAP) refers to pneumonia developing in mechanically ventilated patients after $48 \mathrm{hrs}$. VAP is a complication of invasive mechanical ventilatory support. ${ }^{1}$ The estimated prevalence of ventilatorassociated pneumonia in ICU setting range from $10 \%$ to $65 \%$ with case fatality of more than $20 \%$ in most reported studies. ${ }^{3}$ Each episode prolongs the hospital stay by 4 - 9 days at considerable cost. 4

The accurate diagnosis of VAP remains challenging. The Clinical Pulmonary Infection Score (CPIS) original or modified has been proposed for the diagnosis and management of ventilator-associated pneumonia. 5 Incorporating microbiological results into this score helps in clinical decision making among patients with clinically suspected pneumonia. ${ }^{5}$

One of the major novel strategies involved in preventing VAP requires adequate suctioning. During Open Endotracheal Suctioning (OES), the patient is temporarily removed from 
the ventilator while Endotracheal Suctioning (ETS) is performed. ${ }^{6}$ Endotracheal tubes meant for subglottic suctioning have port for suction above the cuff. With Closed Endotracheal Suctioning (CES), the patient remains attached to the ventilator and an inline/ enclosed catheter is used for ETS. 6

This study was designed to analyse the incidence of ventilator associated pneumonia and length of Intensive Care Unit stay comparing two different techniques of suctioning in mechanically ventilated patients. These patients managed by two different techniques were grouped as Group OES and Group SS + CES. Group OES involves patients managed by Open Endotracheal Suctioning. Group SS + CES involves patients managed by Subglottic Suctioning and Closed Endotracheal Suctioning.

\section{MATERIALS AND METHODS}

This was a prospective randomised clinical trial conducted in Intensive Care Unit of Tertiary Care Centre in India. After approval of Hospital Ethical Committee, 40 patients aged 1865 yrs. who were placed on mechanical ventilator support were included in the study. Patients were randomised by using computer generated into two groups, Group OES and Group SS + CES. Conventional ETTs were changed to ETTs with subglottic suction port above the cuff in those patients who were designated to Group SS + CES. All those patients intubated with conventional ETT were managed by Open Endotracheal Suctioning and designated to Group OES. Those patients who were intubated with ETT having subglottic suction port, managed by subglottic suctioning and closed endotracheal suctioning were designated to Group SS + CES. Exclusion criteria included paediatric age group, patients with pneumonia, other lung co-morbidities, immunosuppressed patients, patients having undergone organ transplantation, any other severe co-morbidities or Acute Physiological And Chronic Health Evaluation II (APACHE) score $>20$.

In Group OES patients after pre-oxygenation if required, suctioning was performed at least once every $8 \mathrm{hrs}$. or as on required basis [visible/ audible secretions, change in ventilator graphics (saw tooth appearance), high PIP, coarse crackles, suspicion of aspiration, to collect sample, unexplained worsening of hypoxia/ hypercapnia]. Using sterile conditions for the entire procedure, suction catheter of less than half the internal diameter of endotracheal tube was selected, and vacuum pressure was set at less than 150 mmHg. Assistant was asked to hand over the catheter and catheter was connected to suction using left hand, Assistant was then asked to disconnect ETT from catheter mount and hand over the ETT to an individual performing suction. Holding the ETT in left hand, catheter was pinched/ suction blocked with right hand and go till just the tip of the tube (30-32 cm). Deep suctioning was avoided, as it can induce cough/ bronchospasm or may cause trauma. The pinch was released, and the catheter was withdrawn gradually with rolling motion of the fingers. Total time taken for the entire suctioning procedure was less than 15 secs. Sedation was considered prior to suctioning, if patient is agitated or has irritable airways. Manual recruitment was done if patient became hypoxic after suctioning. Saline instillation was not done routinely, as it can dislodge microfilm formed over ETT.
ETT with subglottic drain has port just above the cuff. CES unit has T-piece connector, one end for ETT and the other for Ventilator Circuit and third end for MDI adaptor/ nebulizer. Soft sleeve is present over the catheter to maintain sterility while inserting catheter into the ETT. Locking control with thumb valve is meant to control suctioning. It has lavage irrigation port for NSI and suction port.

In Group SS + CES patients, frequency of suctioning, indications and vacuum pressure, catheter size, total time taken were same as Group A patients. After subglottic suctioning, closed endotracheal suctioning was done inserting catheter only to the tip of endotracheal tube. Suction catheter with graduated markings were used. CES comes with locking control. Thumb pressure was applied to unlock it and suctioning was performed after suctioning catheter was withdrawn completely till its housing and flushed with normal saline. After the entire procedure, lock was applied to turn off the suction.

In the ICU, all other identical protocols were used for both groups including hand washing, oral care, use of HME filters, checking of cuff pressure four hourly, DVT prophylaxis, stress ulcer prophylaxis, enteral feeding in head-up position, empirical antibiotic therapy based on Hospital Infection Control Committee recommendations and culture and sensitivity reports, sedation breaks and daily assessment for weaning was done.

Ventilator associated pneumonia was defined as a clinical Pulmonary Infection Score (CPIS) of more than six along with significant quantitative culture of an endotracheal sample $\left(>10^{6} \mathrm{CFU} / \mathrm{mL}\right.$ ) in a patient on mechanical ventilation for over 48 hrs. ${ }^{11}$ CPIS scoring was based on six clinical parameters: Temperature, total leucocyte count, quality of tracheal aspirate, oxygenation, radiographic findings and semi-quantitative culture of tracheal aspirate (Table 1). ICU discharge criteria included fully conscious, alert, oriented haemodynamically stable, not on oxygen support for last 24 hrs., not on any vasopressor/ inotropic support and off invasive mechanical ventilatory support since last $24 \mathrm{hrs}$.

Age, gender, APACHE scores, CPIS score and ICU stay were recorded. All previous studies have been done comparing open endotracheal suctioning with closed endotracheal suctioning. The distribution of data related to categorical variables were expressed as frequency and percentage. Chi-square test was used to compare the difference in percentage of incidence of VAP between two groups. Age, APACHE-II score, duration of mechanical ventilation and duration of ICU stay was expressed as mean with standard deviation or median with range. The comparison of these variables between the groups were carried out by using Mann-Whitney U-test based on distribution of data. A p $<0.05$ was considered statistically significant.

The sample size was calculated using the OpenEpi Version 3 software. The sample size was calculated using the duration of stay in ICU between two groups, Group OES and Group SS + CES. The mean duration of stay in ICU for Group OES was $7.00 \pm 1.25$ days and Group SS + CES was $5.40 \pm 0.84$ days. The power of the study was taken to be $80 \%$ and Confidence Interval (CI) of $95 \%$ was taken. A total sample size of 40 was calculated with sample size of Group OES and Group SS + CES being 20 each. 


\section{RESULTS}

A total of forty patients were included in the study. Patients were comparable in age, gender and APACHE scores [Table 2]. The diagnosis of patients placed on invasive mechanical ventilator support included in this study are represented in Table 3.

The overall incidence of VAP rate based on clinical scoring and culture reports was $30 \%$. Nine (45\%) patients in Group OES and three (15\%) patients in Group SS + CES developed VAP. VAP rate was statistically significantly reduced in Group SS + CES (Table 4).

ICU stay were significantly lesser in patients intubated with ETT having subglottic suction port above the cuff and managed by closed endotracheal suctioning (Group SS + CES) (median, 6 days; interquartile range: 5 - 7) compared to patients intubated with conventional ETT and managed by OES (Group OES) (median, 7; interquartile range: 6 - 9) (Table 4). There was no difference found in their mortality rate (Table 4).

\begin{tabular}{|c|c|c|c|}
\hline CPIS Points & $\mathbf{0}$ & $\mathbf{1}$ & $\mathbf{2}$ \\
\hline $\begin{array}{c}\text { Tracheal } \\
\text { secretions }\end{array}$ & Absent & $\begin{array}{c}\text { Not } \\
\text { Purulent }\end{array}$ & $\begin{array}{c}\text { Abundant and } \\
\text { Purulent }\end{array}$ \\
\hline $\begin{array}{c}\text { Leucocyte count } \\
\left(\mathrm{mm}^{3}\right)\end{array}$ & $\begin{array}{c}>4000 \text { and } \\
<11,000\end{array}$ & $\begin{array}{c}<4000 \text { and } \\
>11,000\end{array}$ & $\begin{array}{c}<4000 \text { or } \\
>11,000\end{array}$ \\
\hline $\begin{array}{c}\text { Temperature } \\
\left({ }^{\circ} \mathrm{C}\right)\end{array}$ & $\begin{array}{c}>36.5 \text { and } \\
<38.4\end{array}$ & $\begin{array}{c}>38.5 \text { and } \\
<38.9\end{array}$ & $>39$ or $<36$ \\
\hline $\begin{array}{c}\mathrm{PaO}_{2} / \mathrm{FiO}_{2} \text { ratio } \\
(\mathrm{mmHg})\end{array}$ & $>240$ or ARDS & - & $\begin{array}{c}<240 \text { or no } \\
\text { ARDS }\end{array}$ \\
\hline $\begin{array}{c}\text { Chest radiograph } \\
\text { Culture of }\end{array}$ & No infiltrate & $\begin{array}{c}\text { Diffuse } \\
\text { infiltrate }\end{array}$ & $\begin{array}{c}\text { Localised } \\
\text { infiltrate }\end{array}$ \\
\hline $\begin{array}{c}\text { Nracheal aspirate }\end{array}$ & Negative & - & Positive \\
\hline \multicolumn{2}{|l|}{ Table 1. Clinical Pulmonary Infection Score } \\
\hline
\end{tabular}

ARDS- Acute Respiratory Distress Syndrome, CPISClinical Pulmonary Infection Score.

\begin{tabular}{|c|c|c|c|}
\hline $\begin{array}{c}\text { Patient } \\
\text { Characteristics }\end{array}$ & $\begin{array}{c}\text { Group OES } \\
(\mathbf{n = 2 0 )}\end{array}$ & $\begin{array}{c}\text { Group SS + } \\
\text { CES (n= 20) }\end{array}$ & P \\
\hline $\begin{array}{c}\text { Age (years, } \\
\text { Mean } \pm \text { SD) }\end{array}$ & $44.15+13.01$ & $44.8+14.04$ & 0.88 \\
\hline $\begin{array}{c}\text { Gender (male: } \\
\text { female ratio) }\end{array}$ & $10: 10$ & $10: 9$ & 0.87 \\
\hline $\begin{array}{c}\text { APACHE II score } \\
\text { median (IQR) }\end{array}$ & $16(15-17)$ & $16.5(15-18)$ & 0.10 \\
\hline Table 2. General Characteristics of Group OES and Group \\
SS + CES \\
\hline
\end{tabular}

$\mathrm{P}<0.05$ was considered as significant, APACHE- Acute Physiological and Chronic Health Evaluation; SD- Standard Deviation; IQR- Interquartile Range; OES- Open Endotracheal Suctioning; SS + CES- Subglottic Suctioning and Closed Endotracheal Suctioning.

\begin{tabular}{|c|c|c|}
\hline Diagnosis & $\begin{array}{l}\text { Group OES } \\
(n=20)\end{array}$ & $\begin{array}{c}\text { Group SS + CES } \\
(\mathrm{n}=20)\end{array}$ \\
\hline Closed Head Injury & 6 & 7 \\
\hline Perforation Peritonitis & 6 & 5 \\
\hline $\begin{array}{l}\text { Strangulated Inguinal } \\
\text { Hernia }\end{array}$ & 4 & 3 \\
\hline Blunt Trauma Abdomen & 2 & 3 \\
\hline Gut Gangrene & 2 & 2 \\
\hline \multicolumn{3}{|c|}{$\begin{array}{c}\text { Table 3. Patient Characteristics of Group OES and Group } \\
\text { SS+ CES and their Diagnosis }\end{array}$} \\
\hline
\end{tabular}

OES- Open Endotracheal Suctioning; SS + CES- Subglottic Suctioning and Closed Endotracheal Suctioning.

\begin{tabular}{|c|c|c|c|}
\hline Outcomes & $\begin{array}{c}\text { Group OES } \\
\text { (n= 20) }\end{array}$ & $\begin{array}{c}\text { Group SS+ } \\
\text { CES (n= 20) }\end{array}$ & P \\
\hline VAP cases (\%) & $9(45 \%)$ & $3(15 \%)$ & 0.04 \\
\hline $\begin{array}{c}\text { Duration of } \\
\text { Ventilation days; } \\
\text { median (IQR) }\end{array}$ & $4.5(3-6)$ & $3(3-4)$ & 0.04 \\
\hline $\begin{array}{c}\text { Duration of ICU stay; } \\
\text { median (IQR) }\end{array}$ & $7(6-9)$ & $6(5-7)$ & 0.03 \\
\hline CPIS; median (IQR) & $5(4-7)$ & $4(4-5)$ & 0.04 \\
\hline Mortality (\%) & $2(10 \%)$ & $1(5 \%)$ & 0.54 \\
\hline
\end{tabular}

Table 4. Study outcome of Group OES and Group SS + CES

$\mathrm{P}<0.05$ was considered as significant. VAP- VentilatorAssociated Pneumonia; ICU- Intensive Care Unit; IQRInterquartile Range; CPIS- Clinical Pulmonary Infection Score.

\section{DISCUSSION}

The overall incidence of VAP in our study was $30 \%$, which is consistent with VAP rates in developing countries of around 15-30\%.7 Usefulness of Subglottic Suctioning and Closed Endotracheal Suctioning as compared to Open Endotracheal Suctioning was compared in this study. Among the 20 patients who were managed by Subglottic Suctioning and Closed Endotracheal Suctioning, three developed VAP in comparison to nine patients who developed VAP among 20 patients managed by Open Endotracheal Suctioning. There was reduction in VAP rate while using Subglottic Suctioning and Closed Endotracheal Suctioning. This reduction was clinically and statistically significant.

Endotracheal tubes with high-volume low-pressure cuffs were used to provide adequate seal to upper airways. As suggested by infrequent association of VAP with bacteraemia, the majority of these infections appear to result from microaspirations of potential pathogens that have colonised the mucosal surfaces of oropharyngeal airways. Intubation of the patient not only compromises the natural barrier between the oropharynx and trachea, but may also facilitate the entry of bacteria into the lung by pooling and leakage of contaminated secretions (Microaspirations) around the endotracheal tube cuff. ${ }^{1}$ These microaspirations of contaminated oropharyngeal and gastric secretions could be one of the causes for developing VAP.

Endotracheal tubes meant for subglottic suctioning have port for suction above the cuff. Subglottic port above the cuff is meant to drain secretions above the cuff. Various studies have used Continuous Subglottic Suction (CSS) and Intermittent Subglottic Suction.8,9 Subglottic secretion drainage during mechanical ventilation results in a significant reduction in VAP, including late-onset VAP. ${ }^{9}$ In those at risk for ventilator-associated pneumonia, the use of endotracheal tubes with subglottic secretion drainage is effective for the prevention of ventilator-associated pneumonia and may be associated with reduced duration of mechanical ventilation and intensive care unit length of stay. ${ }^{10,11}$

In our study, Open Endotracheal Suctioning (OES) was done in those intubated with conventional ETTs. During OES the patient was temporarily removed from the ventilator while ETS is performed.12,13 Some studies have shown that there is more secretion removal with OES.9,10 Patients 
intubated with ETTs having Subglottic suction port were managed by CES. With CES, the patient remains attached to the ventilator and an inline/ enclosed catheter was used for ETS. This helps prevent both the loss of positive end expiratory pressure (PEEP) and the loss of lung volume. ${ }^{6}$ The use of CES may prevent hypoxia and decreases in lung volume for both paediatric and adult patients.6,13 Using CES also has the potential for lessening the spread of infection to patients and staff.6,11 Most clinical staff prefer CES for the ease of use, less time involved and better patient toleration. ${ }^{6}$

Some studies have shown no significant difference in Ventilator Associated Pneumonia (VAP) occurrence between open or closed endotracheal suctioning.6,13 According to Morrow and Argent, and Pedersen et al,6,13 no studies have shown generally an overall superiority between OES and CES.

Our study showed a statistically and clinically significant reduction in the number of days patients spent in ICU when ventilated using subglottic suction drainage and closed endotracheal suctioning.

This study was performed in a single ICU and hence the results are not applicable to all ICUs. The incidence of VAP varies in surgical and non-surgical patients and also depends on the type of surgery. Further, VAP was diagnosed based on Clinical Pulmonary Infection Score. The clinical pulmonary infection score has low diagnostic accuracy. 5 Our study did not differentiate between early and late VAP. Finally, being a pilot study, our sample size may be inadequately powered to detect a difference.

\section{CONCLUSION}

The VAP rate and length of ICU stay were significantly lesser with the ETTs having subglottic suction port above the cuff and managed by subglottic suctioning and closed endotracheal suctioning.

\section{REFERENCES}

[1] Fagun JY, Chastre J. Nosocomial pneumonia. In: Grenvik A, Shoemaker WC, Holbrook PR, et al. eds. Textbook of critical care. $4^{\text {th }}$ edn. Singapore: WB Saunders 2000: p. 1572-94.

[2] Suhas P, Kundra P, Cherian A. Polyurethane cuffed versus conventional endotracheal tubes: effect on ventilator associated pneumonia rates and length of Intensive Care Unit stay. Indian J Anaesth 2016;60(3):163-7.
[3] American Thoracic Society. Hospital-acquired pneumonia in adults: diagnosis, assessment of severity, initial antimicrobial therapy and preventive strategies. A consensus statement, American Thoracic Society, November 1995. Am J Respir Crit Care Med 1996;153(5):1711-25.

[4] Grossman RF, Fein A. Evidence based assessment of diagnostic tests for ventilator associated pneumonia. Executive summary. Chest 2000;117(4 Suppl 2):177S81S.

[5] Fartoukh M, Maitre B, Honore S, et al. Diagnosing pneumonia during mechanical ventilation: the clinical pulmonary infection score revisited. Am J Respir Crit Care Med 2003;168(2):173-9.

[6] Pedersen C, Rosendahl-Nielsen M, Hjermind J, et al. Endotracheal suctioning of the adult intubated patient-What is the evidence? Intensive Crit Care Nurs 2009;25(1):21-30.

[7] Gadani H, Vyas A, Kar AK. A study of ventilatorassociated pneumonia: incidence, outcome, risk factors and measures to be taken for prevention. Indian J Anaesth 2010;54(6):535-40.

[8] Shorr AF, O'Malley PG. Continuous subglottic suctioning for the prevention of ventilator-associated pneumonia. Chest 2001;119(1):228-35.

[9] Lacherade JC, De Jonghe B, Guezennec P, et al. Intermittent subglottic secretion drainage and ventilator-associated pneumonia: a multicenter trial. Am J Respir Crit Care Med 2010;182(7):910-7.

[10] Muscedere J, Rewa O, McKechnie K, et al. Subglottic secretion drainage for the prevention of ventilatorassociated pneumonia: a systematic review and metaanalysis. Crit Care Med 2011;39(8):1985-91.

[11] Dezfulian C, Shojania K, Collard HR, et al. Subglottic secretion drainage for preventing ventilatorassociated pneumonia: a meta-analysis. Am J Med 2005;118(1):11-8.

[12] Clifton-Koeppel R. Endotracheal tube suctioning in the newborn: a review of the literature. Newborn Inf Nurs Rev 2006;6(2):94-9.

[13] Morrow BM, Argent AC. A comprehensive review of pediatric endotracheal suctioning: effects, indications, and clinical practice. Pediatr Crit Care Med 2008;9(5):465-77. 